\title{
Valve-sparing aortic root replacement and remodeling with complex aortic valve reconstruction in children and young adults with moderate or severe aortic regurgitation
}

\author{
Patrick O. Myers, MD, ${ }^{\mathrm{a}, \mathrm{b}}$ Pedro J. del Nido, MD, ${ }^{\mathrm{a}}$ Sitaram M. Emani, MD, ${ }^{\mathrm{a}}$ Gerald R. Marx, MD, ${ }^{\mathrm{c}}$ and \\ Christopher W. Baird, MD
}

\begin{abstract}
Objectives: The durability of valve-sparing aortic root procedures with aortic regurgitation due to leaflet disease is questioned. Here, we review our experience in combined aortic root and valve reconstruction in children and young adults.
\end{abstract}

\begin{abstract}
Methods: All valve-sparing aortic root procedures from 2000 to 2012 were reviewed, and patients with aortic valve repair beyond resuspension were included. Root procedures were classified as replacement with reimplantation, root remodeling, or aortic annular and sinotubular junction stabilization. The primary end point was structural valve deterioration, a composite of aortic valve reoperation and/or moderate or greater regurgitation at follow-up.
\end{abstract}

\begin{abstract}
Results: Thirty-four patients were included during the study period. The surgery consisted of reimplantation in 13 patients, remodeling in 16 patients, and annular and sinotubular junction stabilization in 5 patients. Valve repair consisted of leaflet procedures in 26 patients and subannular reduction in 15 patients. During a median follow-up of 4.2 months (range, 2 weeks- 8 years), there were 5 reoperations for aortic valve replacement due to aortic regurgitation, and 2 patients presented with moderate or greater regurgitation. Freedom from structural valve deterioration was $70.1 \% \pm 10.3 \%$ at 1 year and remained stable thereafter, although it was significantly worse in the reimplantation group $(P=.039)$. A more severe degree of preoperative aortic regurgitation $(P=.001)$ and smaller graft to aortic annulus ratio $(P=.003)$ were predictors of structural valve deterioration.
\end{abstract}

Conclusions: Valve-sparing root and valve reconstruction can be done with low operative risk and allows valve preservation in most patients. These data should question the assumption that reimplantation is superior when associated with complex valve reconstruction. (J Thorac Cardiovasc Surg 2014;147:1768-76)

Aortic root dilation is uncommon in children, and is mostly related to congenital heart disease and its repair or to connective tissue disorders. ${ }^{1-3}$ Aortic root replacement or remodeling is indicated to avoid the risk of progressive valvular incompetence, aneurysm rupture, and dissection, although these are extremely rare events and criteria for surgical management have not been defined in the pediatric population. ${ }^{4}$

Valve-sparing aortic root replacement with reimplantation has obvious advantages over composite graft or

\footnotetext{
From the Departments of Cardiac Surgery, ${ }^{\mathrm{a}}$ and Cardiology, ${ }^{\mathrm{c}}$ Boston Children's Hospital and Harvard Medical School, Boston, Mass; and Department of Cardiovascular Surgery, ${ }^{\mathrm{b}}$ Geneva University Hospitals and School of Medicine, Geneva, Switzerland.

Disclosures: Authors have nothing to disclose with regard to commercial support.

Read at the 93rd Annual Meeting of The American Association for Thoracic Surgery, Minneapolis, Minnesota, May 4-8, 2013.

Received for publication April 7, 2013; revisions received Feb 11, 2014; accepted for publication Feb 18, 2014; available ahead of print March 22, 2014.

Address for reprints: Christopher W. Baird, MD, Department of Cardiac Surgery, Boston Children's Hospital and Harvard Medical School, 300 Longwood Ave, Bader 273, Boston, MA 02115 (E-mail: christopher.baird@ childrens.harvard.edu). 0022-5223/\$36.00

Copyright $($ C 2014 by The American Association for Thoracic Surgery

http://dx.doi.org/10.1016/j.jtcvs.2014.02.055
}

homograft root replacement and aortic root remodeling, and is progressively being introduced for root replacement in children. Although long-term data in adults have shown excellent results, ${ }^{5}$ outcomes following valve-sparing aortic replacement with reimplantation for children with an aortic root aneurysm are sparse and the literature has suggested that valve-sparing procedures, especially root remodeling, may have a higher failure rate. ${ }^{2}$

Aortic regurgitation or anomalous leaflet anatomy usually precludes valve-sparing aortic root procedures for aneurysmal disease. However, avoiding valve replacement in a growing child, or at least delaying it as long as possible, is desirable particularly because aortic valve repair in children has shown excellent long-term results. ${ }^{6-9}$ Just as the indications for valve-sparing root replacement are expanding in adults to include patients with aortic valve insufficiency ${ }^{10,11}$ or even as an adjunct to valve repair to increase the durability of aortic valve repair in selected adults, ${ }^{12-14}$ interest in combined aortic valve reconstruction and aortic root replacement in pediatric populations has emerged. The objective of our study was to review our initial experience in combined aortic root replacement or remodeling with complex aortic valve reconstruction. 

Abbreviations and Acronyms
STJ $=$ sinotubular junction
$\mathrm{SVD}=$ structural valve deterioration

\section{METHODS}

\section{Study Design}

We retrospectively reviewed all patients who underwent aortic valve-sparing root procedures at our institution between 2000 and 2012 . Patients with moderate or severe aortic regurgitation before repair, and who underwent aortic root procedures and aortic valve repair beyond resuspension, were included. Root procedures were classified as root replacement with reimplantation (David procedure) or root remodeling (Yacoub procedure or other techniques other than a David reimplantation procedure). The primary end point was structural aortic valve deterioration (SVD), a composite of aortic valve reoperation and/or moderate or greater aortic regurgitation at follow-up. Clinical or treatment variables were recorded to determine predictors SVD. All patients underwent follow-up to death or June 2012. The study was approved by the Boston Children's Hospital Institutional Review Board and individual patient consent was waived.

\section{Surgical Technique}

Cardiopulmonary bypass with moderate systemic hypothermia was used in all patients. Myocardial protection consisted of antegrade magnesium-lidocaine blood cardioplegia. The surgical techniques used for aortic root and valve repair were chosen by the operating surgeon based on the mechanisms of regurgitation and aortic root pathology. A dilated annulus was usually reduced by placing either a subannular felt strip sutured to the left ventricular outflow tract with externalized sutures, or a cut ring of tube graft placed externally and below the coronary arteries, sutured using interrupted pledgeted sutures, or a David valve-sparing aortic root replacement with reimplantation. Individually dilated sinuses of Valsalva were plicated; resected and the aortic root reapproximated primarily or replaced with a tongue of graft; or the entire root was entirely replaced either with a David valve-sparing aortic root replacement with reimplantation or Yacoub aortic root remodeling, splitting a tube graft to accommodate the 3 aortic commissures. The techniques used were variable and adapted to the underlying disease and surgeon preference.

\section{Statistical Analysis}

Statistical analyses were performed with SPSS software (version 21, IBM-SPSS Inc, Armonk, NY). Data are presented as mean \pm standard deviation or median (range) where appropriate. Regarding the aortic dimensions, the following dimensions were used and normalized using $z$ scores: the aortic annulus, aortic root (measured as the largest dimension of the sinuses of Valsalva), and sinotubular junction (STJ). Continuous variables were analyzed with 1-way analysis of variance or the Kruskal-Wallis test when appropriate, and categorical variables using the $\chi^{2}$ test or Fisher exact test. Actuarial estimates were calculated using the Kaplan-Meier method and differences between curves were assessed by the log-rank test. All statistical tests were 2 -tailed and $P<.05$ was taken as significant.

\section{RESULTS}

\section{Valve-Sparing Aortic Root Procedures}

Among 48 valve-sparing aortic root procedures conducted during the study period, 34 patients presented with moderate or severe aortic regurgitation before repair and their repair included aortic or neoaortic valve reconstruction and were included in the study.

Aortic root procedures consisted of a valve-sparing aortic root replacement following a David V-type reimplantation (reimplantation group) in 13 patients, valve-sparing aortic root remodeling (remodeling group) in 16 patients, and functional annular stabilization by subannular reduction and STJ stabilization with a tube graft in 5 patients. All included procedures were on the systemic semilunar valve and root; that is, aortic for patients with normally related great vessels, or the neoaortic root and valve for patients with dextro-transposition of the great arteries after an arterial switch operation. Root remodeling procedures $(n=16)$ consisted of Yacoub-type aortic root replacement of all 3 sinuses of Valsalva in 5 patients $(31.3 \%)$ and sinus resection or reduction in 11 patients $(68.8 \% ; 6$ single sinus, 3 double sinus, and 2 triple sinus resection or reduction). A portion of these patients have been reported previously. ${ }^{15}$

\section{Demographics}

Patient baseline characteristics are summarized in Table 1. The mean age at surgery was $15.4 \pm 8.7$ years. Nine patients had connective tissue disorders (3 Marfan syndrome, 4 LoeysDietz syndrome, and 2 unspecified); these patients underwent more reimplantation procedures (6 out of $9 ; 67 \%$ ), compared with those without connective tissue disorders (7 out of 21 ; $33 \% ; P=.11)$. Twenty-one patients had previously repaired congenital heart disease. Three patients had coronary anomalies: 1 with single coronary ostium, 1 with intramural right coronary artery, and 1 patient with the left main coronary artery compressed between the neoaortic and neopulmonary roots after an arterial switch operation, along with the circumflex artery from the right coronary artery. There were no significant differences in baseline characteristics between groups; in particular, there was no difference in the proportion of patients with conotruncal anomalies.

\section{Aortic Valve Reconstruction}

Aortic valve repair consisted of leaflet procedures in 26 patients and subannular reduction in 15 patients. Twenty-five patients had annular stabilization. Techniques of aortic root and valve repair are detailed in Table 2. Although there were not any significant differences in valve repair techniques, more patients in the reimplantation group had STJ and aortic annulus stabilization (11 out of 13) than in the remodeling group ( 9 out of $16 ; P=.1$ ), as well as aortic root replacement (13 out of 13 vs 5 out of 16 ; $P<.001)$ and ascending aortic replacement (13 out of 13 vs 8 out of $16 ; P=.003)$. The graft size used did not differ significantly between groups (median, $26 \mathrm{~mm} ; P=.53$ ).

\section{Outcomes and Predictors of SVD}

There were no early deaths. At predischarge echocardiography, 19 patients had no or trivial aortic regurgitation 
TABLE 1. Baseline characteristics between valve-sparing root reimplantation and valve-sparing root remodeling groups

\begin{tabular}{|c|c|c|c|c|}
\hline Variable & $\begin{array}{c}\text { Valve-sparing root } \\
\text { reimplantation }\end{array}$ & $\begin{array}{c}\text { Valve-sparing root } \\
\text { remodeling }\end{array}$ & $\begin{array}{c}\text { Annular and } \\
\text { STJ stabilization }\end{array}$ & $P$ value \\
\hline No. of patients & 13 & 16 & 5 & \\
\hline Age, y & $14.6 \pm 8.7$ & $13.4 \pm 7.0$ & $24.1 \pm 10.3$ & .096 \\
\hline Median aortic regurgitation grade before repair & Moderate & Moderate & Moderate & .14 \\
\hline Connective tissue disorder & $6(46.2)$ & $3(18.8)$ & $0(0)$ & .11 \\
\hline Marfan syndrome & $1(7.7)$ & $2(12.5)$ & $0(0)$ & $>.99$ \\
\hline Loeys-Dietz syndrome & $3(23.1)$ & $1(6.3)$ & $0(0)$ & .34 \\
\hline Congenital heart disease & $6(46.2)$ & $12(75)$ & $3(60)$ & .28 \\
\hline Conotruncal anomalies & $2(15.4)$ & $5(31.3)$ & $2(40)$ & .51 \\
\hline Truncus arteriosus & $0(0)$ & $1(8.3)$ & $1(33.3)$ & .54 \\
\hline DORV & $0(0)$ & $2(16.7)$ & $0(0)$ & .54 \\
\hline Congenital aortic valve disease & $5(62.5)$ & $4(33.3)$ & $1(33.3)$ & .54 \\
\hline D-TGA & $1(12.5)$ & $1(8.3)$ & $0(0)$ & .54 \\
\hline HLHS/SV & $0(0)$ & $3(25)$ & $0(0)$ & .54 \\
\hline ccTGA & $1(12.5)$ & $1(8.3)$ & $1(33.3)$ & .54 \\
\hline Aortic valve anatomy & & & & .55 \\
\hline Quadricuspid & $0(0)$ & $1(6.3)$ & $1(20)$ & \\
\hline Tricuspid & $6(46.2)$ & $9(56.3)$ & $3(60)$ & \\
\hline Bicuspid & $6(46.2)$ & $6(37.5)$ & $1(20)$ & \\
\hline Unicuspid & $1(7.7)$ & $0(0)$ & $0(0)$ & \\
\hline
\end{tabular}

Values are presented as mean \pm standard deviation or $\mathrm{n}(\%)$ unless otherwise noted. STJ, Sinotubular junction; DORV, double-outlet right ventricle; $D$-TGA, dextro-transposition of the great arteries; $H L H S$, hypoplastic left heart syndrome; $S V$, single ventricle; $c c T G A$, congenitally corrected transposition of the great arteries.

$(55.9 \%), 13$ had mild regurgitation $(38.2 \%)$, and 2 had moderate regurgitation $(5.9 \%)$. Both patients with moderate regurgitation were in the remodeling group $(P=.87)$. The mean transvalvular gradient was $8.6 \pm 12.0 \mathrm{~mm} \mathrm{Hg}$, with 2 patients having a gradient $\geq 30 \mathrm{~mm} \mathrm{Hg}(5.8 \%)$. The gradients were not significantly different between groups (reimplantation, $8.7 \pm 10.6 \mathrm{~mm} \mathrm{Hg}$; remodeling, $9.8 \pm 13.9 \mathrm{~mm}$ $\mathrm{Hg}$; annular and STJ stabilization, $4.4 \pm 9.8 ; P=.72)$.

During a median follow-up of 4.2 months (range, 2 weeks-7.75 years), 7 patients presented with SVD: 4 in the reimplantation group $(30.8 \%), 3$ in the remodeling group $(18.8 \%)$, and none in the annular and STJ stabilization group $(P=.46)$ due to 5 reoperations for aortic valve replacement for aortic regurgitation and 2 patients presenting with moderate or greater regurgitation. Freedom from SVD was $75.9 \% \pm 9.4 \%$ at 6 months, $70.1 \% \pm 10.3 \%$ at 1 year, and remained stable thereafter, although it was significantly worse in the reimplantation group $(P=.087$ overall; $P=.039$ comparing reimplantation to remodeling) (see Figure 1).

The mechanism of aortic valve failure was residual leaflet prolapse with an intact repair in 4 patients ( 2 single-leaflet prolapse, 2 trileaflet prolapse), tearing of a left-right coronary commissure suspension suture in 1 patient,

TABLE 2. Surgical techniques of combined valve-sparing aortic root and aortic valve repair

\begin{tabular}{|c|c|c|c|c|}
\hline Variable & $\begin{array}{l}\text { Valve-sparing root } \\
\text { reimplantation }\end{array}$ & $\begin{array}{l}\text { Valve-sparing root } \\
\text { remodeling }\end{array}$ & $\begin{array}{c}\text { Annular and } \\
\text { STJ stabilization }\end{array}$ & $P$ value \\
\hline Leaflet-level aortic valve repair & $12(92.3)$ & $9(56.3)$ & $5(100)$ & .06 \\
\hline Commissuroplasty & $8(61.5)$ & $5(31.3)$ & $2(40)$ & .29 \\
\hline Commissurotomy & $5(38.5)$ & $3(18.8)$ & $2(40)$ & .51 \\
\hline Leaflet central plication & $2(15.4)$ & $1(6.8)$ & $0(0)$ & .74 \\
\hline Leaflet thinning & $4(30.8)$ & $6(25)$ & $2(40)$ & .88 \\
\hline Leaflet patch augmentation & $2(15.4)$ & $3(18.8)$ & $1(20)$ & $>.99$ \\
\hline Annulus-level aortic valve repair: Subannular reduction & $2(15.4)$ & $8(50)$ & $5(100)$ & .003 \\
\hline \multicolumn{5}{|l|}{ Aortic root repair } \\
\hline Annular stabilization & $11(84.6)$ & $9(56.3)$ & $5(100)$ & .10 \\
\hline STJ stabilization & $13(100)$ & $8(50)$ & $5(100)$ & .003 \\
\hline Combined annular and STJ stabilization & $11(84.6)$ & $4(25)$ & $5(100)$ & $<.001$ \\
\hline Aortic root replacement & $13(100)$ & $5(31.3)$ & $0(0)$ & $<.001$ \\
\hline Ascending aorta replacement & $13(100)$ & $8(50)$ & $5(100)$ & .003 \\
\hline Graft size, $\mathrm{mm}$ & $26(14-30)$ & $26(22-30)$ & $28(24-30)$ & .53 \\
\hline
\end{tabular}

Values are presented as median (range) or n (\%). STJ, Sinotubular junction. 


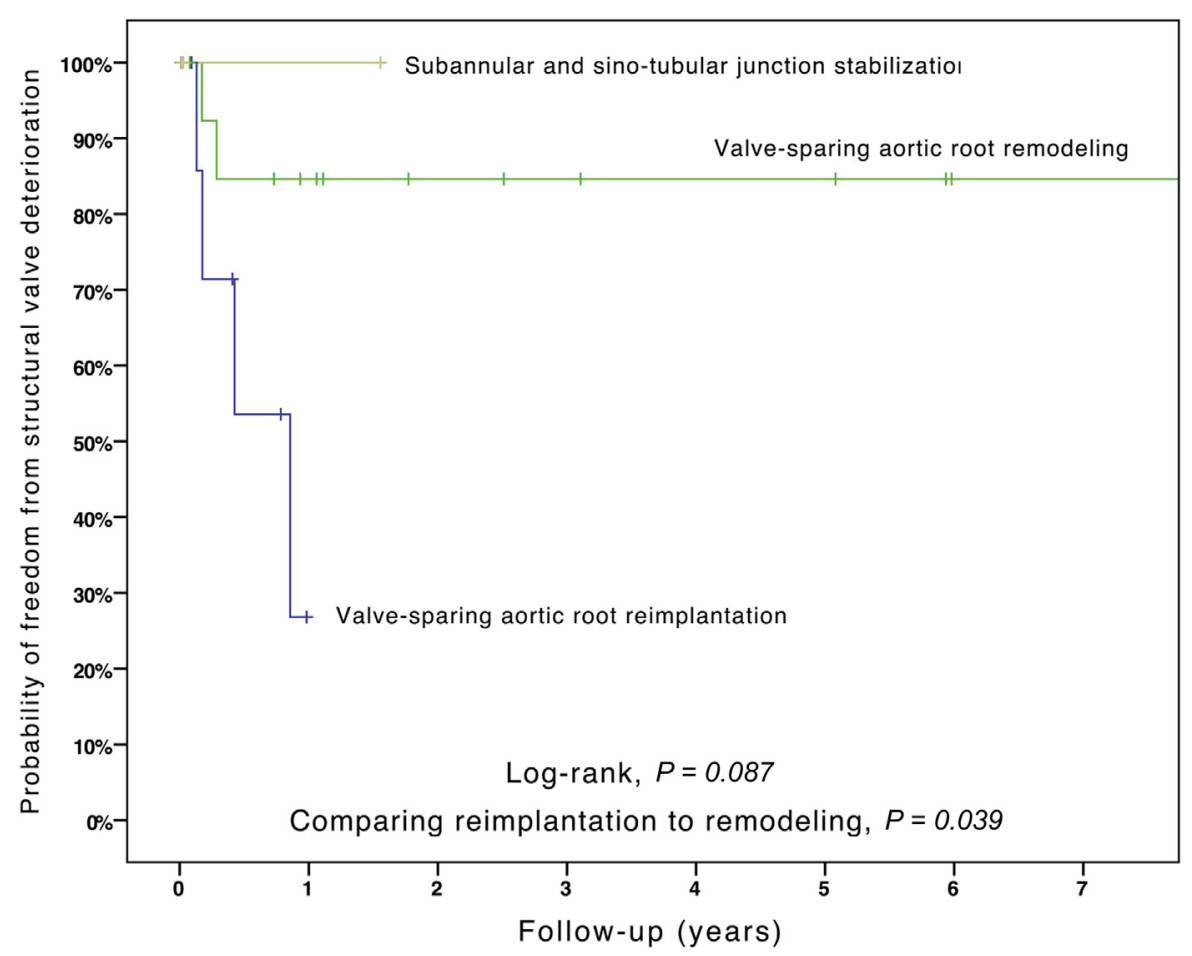

FIGURE 1. Kaplan-Meier estimate of reoperation-free survival, stratified by aortic root procedure groups.

a deficient pericardium-augmented leaflet in 1 patient, and a CorMatrix (CorMatrix Inc, Alfpharetta, Ga) augmented leaflet prolapse with perforations of the native cusp bases in 1 patient.

Because these data suggested a technical issue with graft sizing, the influence of graft size and size relative to the aortic root diameters were investigated. Although the difference in mean ratio of graft size to native aortic annulus and STJ diameter before repair were not significant between groups ( $P=.47$ and $P=.62$, respectively), the reimplantation group had a significantly smaller graft to aortic root diameter ratio $(0.6 \pm 0.08$ vs $0.7 \pm 0.15$ in remodeling group and $0.8 \pm 0.1$ in the annular and STJ stabilization group; $P=.045$ ).

Predictors of SVD are summarized in Table 3. The presence of known connective tissue disorder was not a predictor of SVD ( 2 out of 7 patients [29\%] with SVD vs 7 out of 27 patients [26\%] without SVD; $P>.99$ ). A more severe degree of preoperative aortic regurgitation $(P=.001)$ and a smaller graft to native aortic annulus diameter ratio $(P=.003)$ were the only significant predictors of SVD at univariable analysis.

\section{Aortic Root Dimensions}

In the entire study population, the aortic annulus $z$ score decreased from $2.4 \pm 0.6$ before repair to $1.9 \pm 0.4$ after repair, and further decreased to $1.5 \pm 3.2$ at latest followup. The aortic root $z$ score decreased from $5.7 \pm 2.6$ before repair to $1.5 \pm 2.9$ after repair, and $1.8 \pm 2.8$ at latest follow-up. Finally, the STJ $z$ score decreased from $5.2 \pm 3.2$ before repair to $1.2 \pm 2.5$ after repair, and $1.4 \pm 2.8$ at latest follow-up. The aortic annulus, root, and $\mathrm{STJ} z$ scores stratified by root procedure type are illustrated in Figure 2 and summarized in Table 4.

Although the aortic root, annulus, and STJ $z$ scores were significantly smaller in the reimplantation group after repair $(P=.005, P=.04$, and $P=.03$, respectively), this difference subsided during follow-up, although all dimension $z$ scores remained smaller in the reimplantation group. Furthermore, the aortic annulus and $z$ score were not significantly different if it was stabilized or not $(P=.38$ and $P=.98$, respectively).

\section{DISCUSSION}

Results following Bentall operation have been excellent and reproducible, and have demonstrated long-term durability. ${ }^{16-18}$ Nevertheless, composite replacement with a mechanical prosthesis necessitates lifelong anticoagulation, with lifelong risk of bleeding, thromboembolism, and prosthetic valve endocarditis. ${ }^{17-21}$ These concerns have driven the development of alternative surgical strategies for aortic root replacement, mostly pioneered by the group from Johns Hopkins. ${ }^{1,3}$

Although there is extensive data on aortic valve-sparing root replacement and remodeling in adults, with excellent long-term outcomes, there are relatively little data either 
TABLE 3. Predictors of structural valve deterioration (SVD)*

\begin{tabular}{|c|c|c|c|}
\hline Risk factor & SVD-free & SVD & $P$ value \\
\hline Age, $y$ & $15.7 \pm 9.1$ & $14.5 \pm 7.9$ & .74 \\
\hline Connective tissue disorder & $7(25.9)$ & $2(28.6)$ & 1.00 \\
\hline Loeys-Dietz & $4(14.8)$ & $0(0)$ & .56 \\
\hline Marfan & $3(11.1)$ & $0(0)$ & 1.00 \\
\hline Congenital heart disease & $17(63)$ & $4(57.1)$ & 1.00 \\
\hline Conotruncal anomalies & $6(22.2)$ & $3(42.9)$ & .35 \\
\hline Aortic valve anatomy & & & .18 \\
\hline Unicuspid & $0(0)$ & $1(14.3)$ & \\
\hline Bicuspid & $11(40.7)$ & $2(28.6)$ & \\
\hline Tricuspid & $15(55.6)$ & $3(42.9)$ & \\
\hline Quadricuspid & $1(3.7)$ & $1(14.3)$ & \\
\hline $\begin{array}{l}\text { Preoperative aortic regurgitation } \\
\text { grade, median }\end{array}$ & Moderate & Severe & .001 \\
\hline \multicolumn{4}{|l|}{ Surgical technique } \\
\hline Reimplantation & $9(33.3)$ & $4(57.1)$ & .46 \\
\hline Remodeling & $13(48.1)$ & $3(42.9)$ & .46 \\
\hline Yacoub & $4(22.2)$ & $1(33.3)$ & $>.99$ \\
\hline Sinus reduction or resection & $9(50)$ & $2(66.7)$ & $>.99$ \\
\hline Annular and STJ stabilization & $5(18.5)$ & $0(0)$ & .46 \\
\hline Annular stabilization & $21(77.8)$ & $4(57.1)$ & .35 \\
\hline STJ stabilization & $21(77.8)$ & $5(71.4)$ & $>.99$ \\
\hline Aortic valve repair - leaflet repair & $19(70.4)$ & $6(85.7)$ & .64 \\
\hline Commissuroplasty & $10(37)$ & $5(71.4)$ & .20 \\
\hline Commissurotomy & $7(25.9)$ & $3(42.9)$ & .39 \\
\hline Leaflet thinning & $6(22.2)$ & $4(57.1)$ & .16 \\
\hline Leaflet augmentation & $4(14.8)$ & $2(28.6)$ & .58 \\
\hline Leaflet central plication & $2(7.4)$ & $1(14.3)$ & .51 \\
\hline $\begin{array}{l}\text { Aortic valve repair - subannular } \\
\text { reduction }\end{array}$ & $14(51.9)$ & $1(14.3)$ & .1 \\
\hline Graft size, $\mathrm{mm}$ & $25.6 \pm 4.5$ & $26.4 \pm 3.3$ & .64 \\
\hline Graft to aortic annulus ratio & $1.1 \pm 0.2$ & $0.9 \pm 0.04$ & .003 \\
\hline Graft to aortic root ratio & $0.68 \pm 0.12$ & $0.64 \pm 0.10$ & .51 \\
\hline Graft to STJ ratio & $0.81 \pm 0.20$ & $0.82 \pm 0.03$ & .77 \\
\hline
\end{tabular}

Values are presented as mean \pm standard deviation or $\mathrm{n}(\%)$. STJ, Sinotubular junction. *Defined as aortic valve reoperation or moderate or greater aortic valve regurgitation after repair.

on the (un-) natural history of aortic root aneurysms in children, or defined criteria to indicate when to offer surgery to prevent potential fatal complications of these aneurysms, such as aortic regurgitation, rupture, and dissection. Current management strategies are based more on a heart team approach offering their best expert opinion on when to offer surgical management, and some groups have become increasingly aggressive in proposing this type of surgery. Rahkra and colleagues ${ }^{22}$ reported a policy, if clinically possible, to wait until the size of the aortic root permits implantation of an adult-size graft for a valve-sparing procedure because aneurysm complications occur very seldom, allowing elective aortic root replacement with an adult-size graft. It should be noted that 1 of the 10 patients reported presented acute aortic dissection during clinical follow-up that required urgent management. ${ }^{4}$
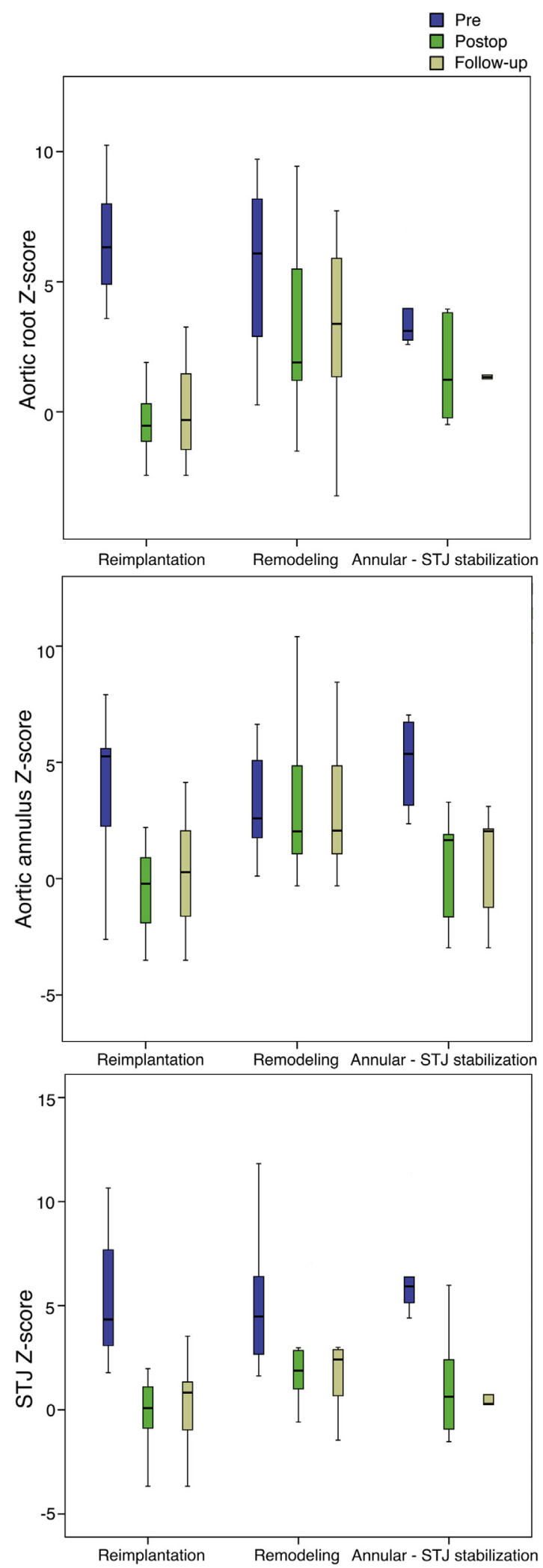

FIGURE 2. Variations of aortic root dimensions stratified by aortic root procedure. STJ, Sinotubular junction. 
TABLE 4. Aortic root dimensions

\begin{tabular}{|c|c|c|c|c|}
\hline Variable & Valve-sparing root reimplantation & Valve-sparing root remodeling & Annular and STJ stabilization & $P$ value \\
\hline \multicolumn{5}{|l|}{ Dimensions before surgery } \\
\hline Aortic annulus, $\mathrm{cm}$ & $2.4 \pm 0.6$ & $2.3 \pm 0.5$ & $2.7 \pm 0.4$ & .31 \\
\hline Aortic annulus $z$ score & $4.0 \pm 3.1$ & $2.9 \pm 2.0$ & $4.9 \pm 2.1$ & .42 \\
\hline Aortic root, $\mathrm{cm}$ & $4.1 \pm 1.1$ & $3.7 \pm 1.1$ & $3.6 \pm 0.7$ & .71 \\
\hline Aortic root $z$ score & $6.5 \pm 2.2$ & $5.9 \pm 3.3$ & $3.9 \pm 1.8$ & .17 \\
\hline $\mathrm{STJ}, \mathrm{cm}$ & $3.3 \pm 1.4$ & $3.0 \pm 0.8$ & $3.7 \pm 0.6$ & .21 \\
\hline STJ $z$ score & $5.3 \pm 3.0$ & $5.2 \pm 2.9$ & $6.6 \pm 2.7$ & .41 \\
\hline \multicolumn{5}{|l|}{ Dimensions after surgery } \\
\hline Aortic annulus, $\mathrm{cm}$ & $1.7 \pm 0.4$ & $2.0 \pm 0.3$ & $2.0 \pm 0.4$ & .29 \\
\hline Aortic annulus $z$ score & $0.1 \pm 2.9$ & $2.9 \pm 3.5$ & $0.4 \pm 2.6$ & .04 \\
\hline Aortic root, $\mathrm{cm}$ & $2.2 \pm 0.5$ & $2.9 \pm 0.5$ & $2.8 \pm 0.5$ & .07 \\
\hline Aortic root $z$ score & $0.4 \pm 1.6$ & $3.6 \pm 3.2$ & $1.7 \pm 2.1$ & .005 \\
\hline $\mathrm{STJ}, \mathrm{cm}$ & $2.0 \pm 0.6$ & $2.3 \pm 0.3$ & $2.4 \pm 0.6$ & .50 \\
\hline STJ $z$ score & $0.1 \pm 1.7$ & $2.4 \pm 2.7$ & $1.3 \pm 3.0$ & .03 \\
\hline \multicolumn{5}{|l|}{ Dimensions at follow-up } \\
\hline Aortic annulus, cm & $1.8 \pm 0.5$ & $2.2 \pm 0.6$ & $2.0 \pm 0.4$ & .29 \\
\hline Aortic annulus $z$ score & $0.3 \pm 2.6$ & $2.4 \pm 3.9$ & $0.6 \pm 2.6$ & .27 \\
\hline Aortic root, $\mathrm{cm}$ & $2.3 \pm 0.5$ & $3.2 \pm 0.9$ & $2.9 \pm 0.5$ & .07 \\
\hline Aortic root $z$ score & $0.2 \pm 1.5$ & $3.6 \pm 3.4$ & $1.4 \pm 1.3$ & .01 \\
\hline $\mathrm{STJ}, \mathrm{cm}$ & $2.2 \pm 0.9$ & $2.4 \pm 0.4$ & $2.3 \pm 0.6$ & .59 \\
\hline STJ $z$ score & $0.8 \pm 3.1$ & $1.9 \pm 2.9$ & $0.9 \pm 2.3$ & .36 \\
\hline
\end{tabular}

Values are presented as mean \pm standard deviation. STJ, Sinotubular junction.

An increasing number of reports have emerged on experience managing aortic root aneurysms in children. ${ }^{1-3,22-24}$ The largest study on valve-sparing aortic root replacement was reported by the group from Johns Hopkins, ${ }^{1}$ reporting on 56 children who underwent valve-sparing root remodeling $(n=12)$ and reimplantation $(n=44)$. That study showed that reimplantation was superior to remodeling in their hands because 4 of the remodeling patients $(33 \%)$ developed significant aortic regurgitation and required aortic valve repair or replacement, whereas none of the reimplantation patients developed significant aortic regurgitation. The mechanism responsible for late aortic regurgitation in the remodeling group was annular dilation. That patient group was different from ours because it was predominantly patients with connective tissue disorders (ie, Marfan, Loeys-Dietz, and Ehlers-Danlos), with only 2 patients not having a connective tissue disorder. Also, only 5 patients $(8.9 \%)$ had more than $2+$ aortic regurgitation (although these were not the patients who developed late aortic regurgitation), and initially any patient with leaflet asymmetry, leaflet fenestration, prolapse, or bicuspid morphology was excluded.

Likewise, Roubertie and colleagues ${ }^{2}$ reported 14 valvesparing root replacements in children (11 remodeling, and 3 reimplantations). In patients with remodeling, 1 patient died and 6 patients required aortic valve replacement, and the authors concluded that remodeling should be abandoned in the pediatric population. All of those patients had connective tissue disorders, and all those with significant aortic regurgitation underwent a Bentall operation $(n=9)$.
Finally, Rahkra and colleagues ${ }^{22}$ reported 10 patients with valve-sparing aortic root replacement with a mean age at repair of 15 years. Four patients had congenital heart disease (ie, tetralogy of Fallot, Taussig-Bing anomaly, and tricuspid atresia), whereas 5 had connective tissue disorders and 1 had Takayasu arteritis. Two patients presented with moderate or severe aortic regurgitation before repair. During a median follow-up of 4.1 years there were no late deaths and 3 reoperations ( 2 for aortic valve replacement and 1 for a sinus of Valsalva false aneurysm).

Our study has several limitations. First, this was a retrospective, noninterventional review designed to evaluate outcomes of an established clinical program. All patients were managed as individuals and not according to a treatment protocol, which would have improved our ability to analyze outcomes. Our analyses were limited by the limited patient sample, even if this represents 1 of the largest populations of valve-sparing root and complex aortic valve repair procedures. Furthermore, the surgical techniques used included various techniques of aortic root repair, as well as many differing underlying anatomies, including complex transposition of the great arteries and single ventricle physiology, which may confound the analysis. Also, surgical techniques were not equally distributed between groups because annuloplasty was inherently a part of reimplantation (compared with 14 out of 21 in patients who had remodeling or annular and STJ stabilization). Finally, the follow-up was relatively short, particularly in the reimplantation group. 
However, we are the first to look specifically at the results of combined valve-sparing aortic root and complex aortic valve repairs in a pediatric population. The finding of worse outcomes in valve-sparing aortic root replacement and reimplantation is, admittedly, surprising and suggests a technical issue, with the interesting finding that the graft to root diameter ratio was smaller in the reimplantation group, and that smaller graft to annulus diameter ratio is a predictor of SVD. Furthermore, 4 patients with SVD had an intact repair, with prolapse of 1 or 3 leaflets. This suggests that the graft during reimplantation may have been undersized, setting up for a higher risk of SVD because this creates a valve with a surface area of cusp tissue too large for the new, downsized annulus with a lower level of cusp coaptation, leading to cusp prolapse and regurgitation. This limited coaptation reserve predisposes to regurgitation. El Khoury and colleagues ${ }^{13}$ have proposed a simple, reproducible technique for graft-sizing for reimplantation, using the height of the interleaflet triangle between the left and noncoronary leaflets, which corresponds to the external diameter of the STJ of a competent aortic valve (and to choose the next larger graft size if the distance does not correspond with a labeled graft size to avoid undersizing).

\section{CONCLUSIONS}

Combined valve-sparing root and aortic valve reconstruction can be done with low operative risk and allows valve preservation in a majority of patients at midterm follow-up. Although root replacement with reimplantation was previously shown to have better outcomes than remodeling in children, these data should caution the same assumption being made when associated with complex aortic valve reconstruction. Adequate graft sizing is important for the durability of repair, and undersizing should be avoided to prevent SVD. Although we did not find that the presence of connective tissue disorder was a risk factor for SVD, we have adopted an institutional policy of repairing the valve at the time of root replacement or remodeling only when minor defects are present.

\section{References}

1. Patel ND, Arnaoutakis GJ, George TJ, Allen JG, Alejo DE, Dietz HC, et al. Valve-sparing aortic root replacement in children: intermediate-term results. Int Cardiovasc Thorac Surg. 2011;12:415-9.

2. Roubertie F, Ben Ali W, Raisky O, Tamisier D, Sidi D, Vouhé PR. Aortic root replacement in children: a word of caution about valve-sparing procedures. Eur J Cardiothorac Surg. 2009;35:136-40.

3. Vricella LA, Williams JA, Ravekes WJ, Holmes KW, Dietz HC, Gott VL, et al. Early experience with valve-sparing aortic root replacement in children. Ann Thorac Surg. 2005;80:1622-6.

4. Konstantinov IE, Fricke TA, D'Udekem Y, Robertson T. Aortic dissection and rupture in adolescents after tetralogy of Fallot repair. J Thorac Cardiovasc Surg. 2010;140:e71-3.

5. David TE, Armstrong S, Manlhiot C, McCrindle BW, Feindel CM. Long-term results of aortic root repair using the reimplantation technique. J Thorac Cardiovasc Surg. 2013;145(3 Suppl):S22-5.
6. Bacha EA, McElhinney DB, Guleserian KJ, Colan SD, Jonas RA, Del Nido PJ, et al. Surgical aortic valvuloplasty in children and adolescents with aortic regurgitation: acute and intermediate effects on aortic valve function and left ventricular dimensions. J Thorac Cardiovasc Surg. 2008;135:552-9.

7. Baird CW, Myers PO, Del Nido PJ. Aortic valve reconstruction in the young infants and children. Sem Thorac Cardiovasc Surg Ped Cardiac Ann. 2012;15: 9-19.

8. d'Udekem Y, Siddiqui J, Seaman CS, Konstantinov IE, Galati JC, Cheung MMH, et al. Long-term results of a strategy of aortic valve repair in the pediatric population. J Thorac Cardiovasc Surg. 2013;145:461-7.

9. Myers PO, Tissot C, Christenson JT, Cikirikcioglu M, Aggoun Y, Kalangos A. Aortic valve repair by cusp extension for rheumatic aortic insufficiency in children: long-term results and impact of extension material. J Thorac Cardiovasc Surg. 2010;140:836-44.

10. Leshnower BG, Guyton RA, Myung RJ, Puskas JD, Kilgo PD, McPherson L, et al. Expanding the indications for the David V aortic root replacement: early results. J Thorac Cardiovasc Surg. 2012;143:879-84.

11. De Kerchove L, Boodhwani M, Glineur D, Poncelet A, Verhelst R, Astarci P, et al. Effects of preoperative aortic insufficiency on outcome after aortic valve-sparing surgery. Circulation. 2009;120(11 Suppl):S120-6.

12. De Kerchove L, Boodhwani M, Glineur D, Vandyck M, Vanoverschelde J-L, Noirhomme P, et al. Valve sparing-root replacement with the reimplantation technique to increase the durability of bicuspid aortic valve repair. $J$ Thorac Cardiovasc Surg. 2011;142:1430-8.

13. Boodhwani M, El Khoury G, De Kerchove L. Graft sizing for aortic valve sparing surgery. Ann Cardiothoracic Surg. 2012;2:140-3.

14. El Khoury G, De Kerchove L. Principles of aortic valve repair. J Thorac Cardiovasc Surg. 2013;145(3 Suppl):S26-9.

15. Myers PO, Bautista-Hernandez V, Del Nido PJ, Marx GR, Mayer JE, Pigula F, et al. Surgical repair of truncal valve regurgitation. Eur J Cardiothorac Surg. 2013;44:813-20.

16. Gott VL, Greene PS, Alejo DE, Cameron DE, Naftel DC, Miller DC, et al. Replacement of the aortic root in patients with Marfan syndrome. New Eng J Med. 1999;340:1307-13.

17. Gott V, Cameron D, Alejo D. Aortic root replacement in 271 Marfan patients: a 24-year experience. Ann Thorac Surg. 2002;73:438-43.

18. Cameron DE, Alejo DE, Patel ND, Nwakanma LU, Weiss ES, Vricella L, et al. Aortic root replacement in 372 Marfan patients: evolution of operative repair over 30 years. Ann Thorac Surg. 2009;87:1344-9.

19. Baer RW, Taussig HB, Oppenheimer EH. Congenital aneurysmal dilatation of aorta associated with arachnodactyly. Bull Johns Hopkins Hosp. 1943;72:309-31.

20. McKusick VA. Cardiovascular aspects of Marfan's syndrome: heritable disorder of connective tissue. Circulation. 1955;11:321-42.

21. Murdoch JL, Walker BA, Halpern BL, Kuzma JW, McKusick VA. Life expectancy and causes of death in Marfan syndrome. New Eng J Med. 1972;286:804-8.

22. Rakhra SS, Brizard CP, D'Udekem Y, Konstantinov IE. Valve-sparing aortic root replacement in children. J Thorac Cardiovasc Surg. 2012;144:980-1.

23. Myers PO, Aggoun Y, Tissot C. Giant aortic root aneurysm in Marfan syndrome: a rare complication in early childhood. J Thorac Cardiovasc Surg. 2011;141: 293-4.

24. Lange R, Badiu CC, Vogt M, Voss B, Hörer J, Prodan Z, et al. Valve-sparing root replacement in children with aortic root aneurysm: mid-term results. Eur J Cardiothorac Surg. 2013;43:958-64.

\section{Discussion}

Dr Duke E. Cameron (Baltimore, $M d$ ). You have described a very valuable experience with a challenging group of patients, namely children with aortic root aneurysms and significant valve disease that is not simply the result of a dilated root. Two-thirds of these patients had already had previous congenital heart repairs. That is what distinguishes your series from most other series, including ours at Hopkins, where the majority of our patients have connective tissue disorders, no previous surgery, and much less aortic regurgitation, often none.

You have demonstrated that these operations are safe and that good outcomes are achievable, at least in early follow-up, in nearly 
three-quarters of your patients. Your intriguing finding is that the patients who had reimplantation procedures had worse outcomes in terms of recurrent aortic regurgitation than those who had remodeling operations. This is in sharp contrast, as you pointed out, with most other reports where reoperation rate and recurrent aortic regurgitation are better with reimplantation presumably because of annular stabilization.

You have also suggested that this may have been a graft sizing problem. Perhaps your grafts were too small for that root and they may have crumpled the valve, induced prolapse, and perhaps forced you to do an aortic valve repair. I suspect you are right, and this is supported by the fact that your reimplantation patients had a much more severe reduction in the root diameter than the remodeling group.

But I disagree with the implication that the problem is the reimplantation technique itself. Indeed, because most of the surgeons here today will be performing these operations in patients with connective tissue disorders, such as Marfan syndrome and Loeys-Dietz syndrome, it is important to stress that annular stabilization, which is achieved reliably only by the reimplantation technique and appropriate graft sizing, are the key to good long-term results. This has been amply demonstrated in both children and adults.

I would also like to challenge the notion that aortic regurgitation often precludes valve-sparing procedures. This depends entirely on the mechanism of regurgitation. If the cusps are normal or they are only mildly stretched and the regurgitation is due to dilation of the annulus or sinotubular junction (STJ), then durable valve competence is often achieved just by reducing the annulus and STJ, as appropriate. With leaflet disease it is a different matter, but it may still be repairable. We should approach each of these cases individually and intraoperative assessment is absolutely crucial.

So my questions are, first, by what method did you choose graft size, and have you changed that approach since reviewing these findings? Second, when you reoperated on patients for AR, what were the findings? Why were the valves leaking?

Finally, I noted in your work that STJ stabilization was achieved in all of your reimplantation patients, which is what we would expect, but only $60 \%$ of the remodeling patients. I do not quite understand that, because both of these operations should stabilize the STJ.

Dr Myers. Thank you very much for the very interesting questions. It is an honor to have questions from such an expert on valve-sparing aortic root procedures.

These procedures were done by 6 to 7 different surgeons who each had his or her own method. The main method used was to evaluate the annular size and approximate into what size graft the leaflets could be resuspended without undergoing a significant aortic valvuloplasty, if that was possible. There was not any systematic formula or measurement, as has been described in adults.

Regarding the mechanism of failure, it was interesting that of the 7 patients who had failure, 4 had an intact repair when the valve was reevaluated surgically, and there was prolapse of all 3 leaflets. This could, again, indicate that the resuspension or the repair had a deficient coaptation height, which progressed to prolapse with time. Although we initially had a favorable result that obviously was not the case over time.
Two patients had issues with leaflet augmentation. In 1 patient the augmented leaflet had retracted, was deficient, and the regurgitant jet was along this leaflet. The second patient had a CorMatrix leaflet (CorMatrix Inc, Alfpharetta, Ga) that, on the other hand, was too floppy and prolapsed past the point of coaptation. The final patient had rupture of resuspension stitches associated with tears in the leaflets that were deemed not to be repairable and so the valve was replaced.

As I showed, the remodeling group is actually quite different from those reported in most of the series and your own, where root remodeling has predominantly been a Yacoub-type operation. Here we have other types of procedures, with sinus reduction and resection or annular and STJ stabilization, and only 5 Yacoub procedures. Overall in this group, it was actually a fairly limited procedure from the aortic root standpoint and more predominantly a procedure on the aortic valve repair. So in these patients most often the annulus was not stabilized and the ascending aorta was not necessarily replaced.

Dr Cameron. There was no Dacron graft?

Dr Myers. No, that is correct.

Dr Christian Pizarro (Wilmington, Del). That is a very intriguing problem that we have been trying to deal with during the past decade. There are data published by Dr David as well as Gebrine El Khoury from Brussels that illustrate a relatively constant, reliable methodology as to how to choose the graft, and that is basically drawing a line between the nadir of the sinuses and measure the distance (height) between this line and the intertrigonal space. This correlates quite closely with the appropriate diameter of a graft, allowing a good match to prevent the issue that when you downsize too much then the valve will sag and then you end up with regurgitation.

I am particularly interested in the group of patients with congenital heart disease. What type of congenital heart disease did you see most commonly? How many of those patients did have a bicuspid valve? Were the distributions different between the 2 techniques? Obviously to do the reimplantation on patients with bicuspid valve is less challenging in terms of obtaining an appropriate geometric arrangement.

Dr Myers. On this slide you see the different types of congenital heart disease, which spanned the whole spectrum of disease. We looked to see if conotruncal anomalies were a predictor of structural valve deterioration, with a subannular area and conus that is much more insecure over time. That was not the case. Overall there were not any significant differences in the congenital heart disease.

In terms of valve anatomy, patients who had truncus arteriosus most often had a quadricuspid valve, had 1 of the leaflets and sinus resected or reduced, and that was probably a patient who was more in the remodeling rather than replacement and reimplantation.

But we also did valve-sparing root replacement with reimplantation in patients with bicuspid aortic valves associated with tricuspidization aortic valvuloplasty.

Dr James Quintessenza (St Petersburg, Fla). These are very challenging patients as we all know, and I would like to push a little bit more on where we think we might be able to improve, especially in patients undergoing reimplantation. I assume when you left the operating room you had 0 to mild regurgitation in those patients and so therefore over time you saw this deterioration? 
Dr Myers. Yes, that is correct.

Dr Quintessenza. We have to assume that we can get a pretty good repair at the time of the operation and something happens in terms of biodegenerative process or fibrosis that then results in insufficiency. That begs the question of the materials we are using and the techniques we are using. It seems like there is a heterogeneous kind of approach to the techniques and the materials.

Dr Myers. That is correct. The techniques were at the operating surgeon's choice, based on the mechanism, and obviously dependent on what the individual surgeons were comfortable doing. With time we have used quite a bit more leaflet patch augmentations and things like that, and we know that there is an issue with the patch material deteriorating or retracting over time, and that obviously goes into the equation of how these valves do later on.

Dr Quintessenza. Do you have any information, for example, of materials that you tried that seemed to fail and prompted you to switch to other materials, and what is your choice for an optimal material now?

Dr Myers. We looked at each 1 of these techniques to see if they were predictors of structural valve deterioration. Because of our limited patient numbers, they were not predictors.

For choice of material, we have been using CorMatrix and have some favorable results with that, and autologous pericardium with a short treatment time with glutaraldehyde.

Dr Quintessenza. The key is to try to figure out what is the best material that does not undergo such changes so that we can achieve a more durable outcome for these patients.

Dr Christopher Caldarone (Toronto, ON, Canada). You had a reasonable number of patients who had a subannular plication and a supravalvar tube graft placement of the ascending aorta. Do you think that is really a valid group to be calling valve-sparing root replacement and to be comparing with the implantation technique?

Dr Myers. That is a very good question and obviously a concern. Professor El Khoury and his group from Belgium have been pushing this as a form of root remodeling. It is not actually addressing the sinuses of Valsalva, but it is addressing the annulus and the STJ, and then we are addressing the leaflets themselves with the aortic valve repair.

Dr Caldarone. It is a fundamentally different repair. So it is just a question of whether it is a valid comparison.

The other question I want to ask is in regard to your intraoperative transesophageal echo results. These valves were all assessed with intraoperative echocardiograms, and it is quite possible to have a competent repair that is not a durable repair if you fail to have an adequate zone of coaptation in the aortic valve leaflets. It would help to refine your analysis by including those intraoperative echocardiogram findings. Those may be the biggest predictor of the durability of these repairs.

Dr Myers. Absolutely. Data in adults have been very clear that the coaptation height has a significant predictive value. There are limited results or data for that in children, and unfortunately we did not measure that systematically, so unfortunately I do not have any data.

Dr Caldarone. You do have the opportunity to get the data.

Dr Myers. Yes, absolutely.

Dr James Tweddell (Milwaukee, Wis). It seems that the remodeling procedures you have done are very different than would be described for the typical child, teenager, or young adult with a connective tissue disorder and a primary aortopathy. It seems like a very mixed bag of strategies used to repair the aortic valve for stenosis or regurgitation, combined with some patients with connective tissue disorder where it has been used to deal with dilated sinuses of Valsalva but not primarily aortic valve pathology. The result is a very difficult comparison within a group of very challenging group of patients.

Dr Myers. I agree.

Dr V. Mohan Reddy (Stanford, Calif). In this mixed bag of patients, was there any difference between trileaflet aortic valve and nontrileaflet aortic valves in terms of interventions?

Dr Myers. No. We looked at valve anatomy as a predictor of structural valve deterioration, but due to the limited patient numbers and events, it was not a predictor of structural valve deterioration.

Dr Reddy. I would have expected the bicuspid aortic valve to be less durable than a trileaflet. 